\title{
Influence of fall height on high impact polystyrene deformation and characteristics of drop weight test
}

\author{
Ales Mizera ${ }^{1, *}$, Petr Chalupa ${ }^{1}$, and Ivan Hudec $^{2}$ \\ ${ }^{1}$ Tomas Bata University in Zlin, nam. T. G. Masaryka 5555, 76001 Zlin, Czech Republic \\ ${ }^{2}$ Faculty of Chemical and Food Technology STU in Bratislava, Radlinskeho 9, 81237 Bratislava 1, Slovakia
}

\begin{abstract}
This study deals with high impact polystyrene (HIPS) which was subjected the drop-weight test. HIPS is a polymer produced by the reaction between butadiene synthetic elastomer and styrene (5-14 \%) which contains the crystal polymer in certain amounts and is commonly used in mechanical engineering applications where machine parts are exposed to impact loading. The injection moulded HIPS samples were subjected the penetration test at different fall heights and the results were subsequently evaluated and discussed. It was found out that all fall heights are suitable for HIPS penetration, but the optimal one is $50 \mathrm{~J}$ because of the smallest variation range. Higher heights are not needed because of increasing power consumption of the test device. From the results, it is clear, that HIPS is not so highly impact resistant material as for example HDPE, because of that is this material suitable for applications where is not often exposed to too big impacts at high velocities.
\end{abstract}

\section{Introduction}

After adding of an elastomer, brittle polystyrene (PS) becomes more ductile. This is how high impact polystyrene (HIPS) arises. HIPS is one of the first toughened systems. In 1948 a process of adding elastomers to rigid plastics in order to increase their fracture resistance was firstly used. The big success of HIPS led to the development of similar blends. HIPS is a polymer produced by the reaction between butadiene synthetic elastomer and styrene (5-14 \%) which contains the crystal polymer in certain amounts. This polymer has higher impact resistant in comparison with unfilled PS and it is also durable against organic liquids, solid oils and liquid oils. End-use properties of HIPS are dependent on many factors such as the concentration and composition, particle size and distribution of the rubber. It has been found out that one of the main factors which affect the impact strength and toughness of this material is the rubber-phase size distribution and particle size. HIPS is mostly used in mechanical engineering applications where machine parts are exposed to impact loading [1-3].

The scientists from Turkey studied the effect of previous impacts on the impact behaviour of HIPS. They measured instrumented Charpy impact tests and set the falling angles of Charpy hammer as 5, 10, 13, 15, 16, 17, 18,19 and $20^{\circ}$. It was realized that there was noticeable crack propagation at $20^{\circ}$. Subsequently, all samples were put into the impact tester and fractured by the Charpy hammer again, but this time at angle of $35^{\circ}$. The scientists called this impact as "final impact". The sample which was firstly impacted at $20^{\circ}$ was fractured during the final impact with a very small energy. This small energy the tester could not measure. It was also found out that crack initiation energies were almost the same for each sample, unlike crack propagation energies increased for the samples previously impacted at 5 and $10^{\circ}$ [2].

Jin Hwan Choi, Kyung Hyun Ahn and Sang Yong Kim studied how the graft degree affects the tensile and dynamic behaviour of HIPS, they found out that the tensile modulus and the yield stress decrease with the graft degree up to $120 \%$ and then increase. The earlier part of this behaviour occurs because of the increase in the stress transferred to the rubber particles and the latter part arrives from huge occlusions which are not enclosed by rubber layers. It was also revealed that the degree of graft depresses the moves of the rubber chain and because of that the glass transition temperature increases [4].

V. Serpoosha, S. Zokae and R. Bagheri dealt with the rubber particle cavitation in HIPS and its influence on mechanical properties and deformation behaviour of this polymer at various temperatures. The samples were subjected of thermal cycles and the creep behaviour was studied. The creep curve of specimen at $-23{ }^{\circ} \mathrm{C}$ and of the ambient temperature had also zero difference, but after lowering the temperature from the ambient temperature to $-44^{\circ} \mathrm{C}$, the creep deformation increased. Three-point-bending test was also measured up to a

\footnotetext{
Corresponding author: mizera@utb.cz
} 
constant load of $200 \mathrm{~N}$. During cooling from the ambient temperature to $-20{ }^{\circ} \mathrm{C}$, the load-displacement curve shifts to the left, it shows that the cooled material is more rigid than the control specimen. The Charpy impact test showed that the Charpy impact strength decreases with an increasing cavitation degree in cooled HIPS specimens and the zones of notch-tip damage in three-point-bending specimens become larger [5].

It is also possible to fill the HIPS with fibres. A team of scientists from Argentina and Spain dealt with HIPS reinforcement with short sisal fibres and with mechanical behaviour of HIPS after this type of filling. They found out that the sisal fibres in HIPS caused an increasing trend in stiffness, while deformation at break and tensile strength decreased. It was probably caused by the poor adhesion between fibres and polymeric matrix. All composites of polymeric matrix and sisal fibres displayed ductile behaviour under both impact loading and quasistatic conditions and in composites, impact fracture toughness decreased in comparison with the polymeric matrix [6].

This study becomes a big benefit for the practice, because it is concentrated on the observation of crack growth an on HIPS behaviour during this process.

\section{Experimental}

Polystyrene was used as the basic polymer material (EDISTIR SR 550 07). An ARBURG Allrounder 470H Advance Injection moulding machine was used for sample preparation, with the processing conditional to comply with polystyrene (PS) producer's recommendations, as can be seen in Tab. 1. The samples were in the shape of plates with dimensions $100 \times 100 \times 3 \mathrm{~mm}$ according to ISO $6603-2$.

Table 1. Setting of injection moulding machine parameters.

\begin{tabular}{|l|l|}
\hline Injection Parameters & Values \\
\hline Injection Pressure $[\mathrm{MPa}]$ & 70 \\
\hline Injection velocity $\left[\mathrm{mm} \cdot \mathrm{s}^{-1}\right]$ & 50 \\
\hline Holding Pressure $[\mathrm{MPa}]$ & 60 \\
\hline Cooling Time $[\mathrm{s}]$ & 20 \\
\hline Mould Temperature $\left[{ }^{\circ} \mathrm{C}\right]$ & 30 \\
\hline Melt Temperature $\left[{ }^{\circ} \mathrm{C}\right]$ & 225 \\
\hline
\end{tabular}

Injection moulded polystyrene samples were tested on drop weight test machine Zwick HIT230F according to

ISO $6603-2$ at ambient temperature $23{ }^{\circ} \mathrm{C}$. As a main parameter was used fall height, however this parameter was re-calculated on impact energy, which was set on the machine. 15 samples at each height $(30,50,100,150$, 200 and $230 \mathrm{~J}$ ) were tested and then maximum impact force was statisticaly evaluated in program TestExpert II and MiniTab. At the end crack surface after the test of each height was evaluated.
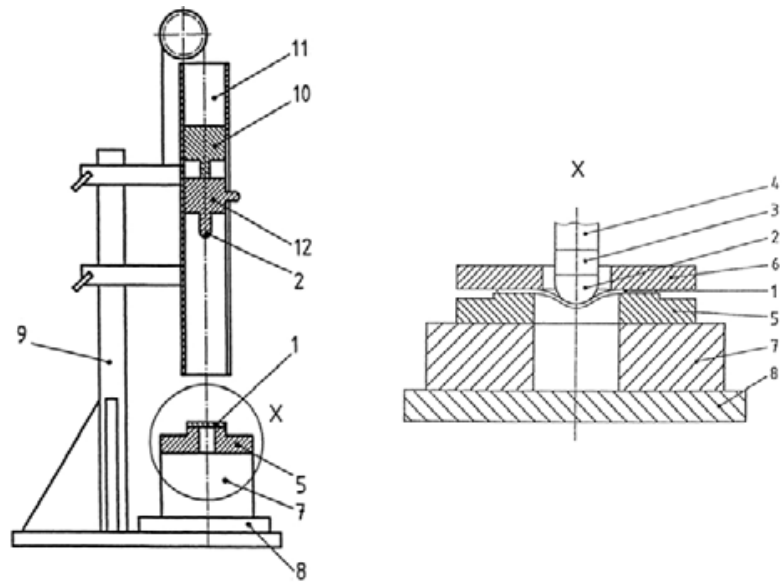

Fig. 1. Falling-dart system.

1 - Test specimen; 2 - Hemispherical striker tip $10 \mathrm{~mm} ; 3$ Force sensor; 4 - Shaft; 5 - Test specimen support; 6 Clamping ring (optional); 7 - Base; 8 - Acoustic isolation (optional); 9 - Stand for falling-dart system; 10 - Holding and release system for weighted striker; 11 - Guide shaft for weighted striker; 12 - Weighted striker $23,77 \mathrm{~kg}$.

\section{Results and discussion}

This study is concentrated on the influence of fall height on high impact polystyrene deformation. Injection moulded HIPS samples were penetrated by penetrator with fall heights in the range from 30 to $230 \mathrm{~J}$ and the results were subsequently evaluated. The conditions of injection moulding are displayed in Table 1 and HIPS statistical evaluation of the measurements is shown in Table 2 .

\subsection{Maximum impact force}

The height of fall was set at all measurements differently and the results are then discussed.

Table 2. HIPS statistical evaluation of the maximum force at the height of the fall.

\begin{tabular}{|c|c|c|c|c|c|c|}
\hline Set energy of fall $[\mathrm{J}]$ & \multirow{2}{*}{30} & \multirow{2}{*}{50} & \multirow{2}{*}{100} & \multirow{2}{*}{150} & \multirow{2}{*}{200} & \multirow{2}{*}{230} \\
\hline Statistical characteristics $[\mathbf{N}]$ & & & & & & \\
\hline Number of measurements & 15 & 15 & 15 & 15 & 15 & 15 \\
\hline Arithmetic mean & 2171 & 2246 & 2228 & 2245 & 2209 & 2186 \\
\hline Type error A & 16 & 8 & 9 & 10 & 9 & 9 \\
\hline Standard deviation & 50 & 25 & 29 & 33 & 27 & 27 \\
\hline Minimum value & 2073 & 2207 & 2180 & 2187 & 2177 & 2160 \\
\hline Median & 2188 & 2251 & 2232 & 2245 & 2200 & 2179 \\
\hline Maximum value & 2227 & 2273 & 2267 & 2307 & 2251 & 2243 \\
\hline Variation range & 154 & 67 & 86 & 119 & 74 & 83 \\
\hline
\end{tabular}




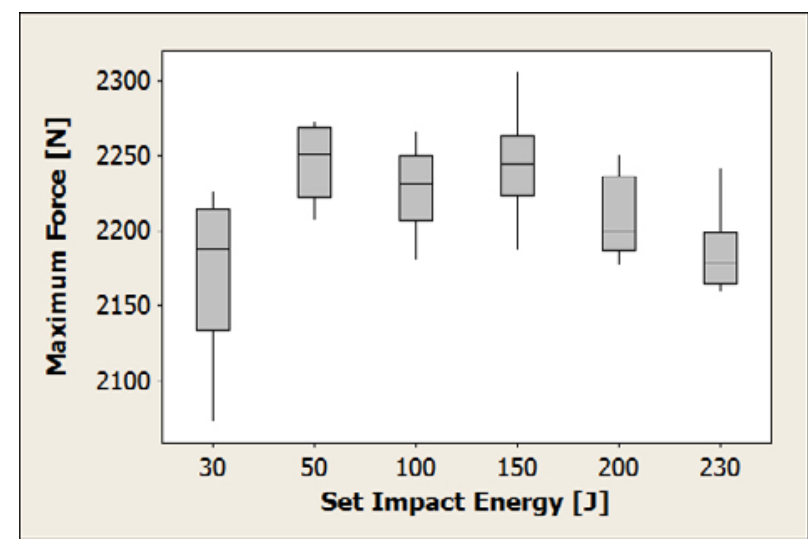

Fig. 2. HIPS Boxplot graph of maximum force at fall height.

In Figure 2 the maximum force at fall height is displayed. Penetration occurred at all fall heights of this material. The value $50 \mathrm{~J}$ looks like the optimal fall height, because the variation range is there the smallest. It is not needed to use higher heights because of increasing power consumption of the test device.

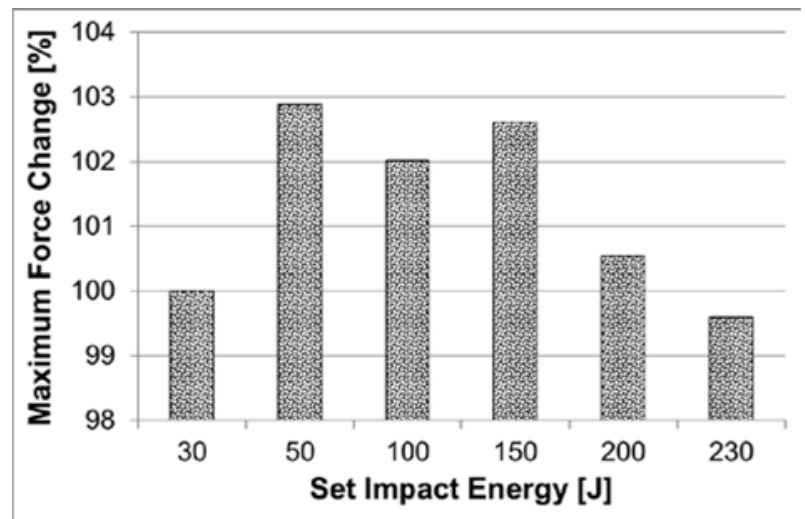

Fig. 3. HIPS percentage change in maximum force to the prescribed base energy of fall $30 \mathrm{~J}$.

The force change in $\%$ during the test can be seen in Figure 3 . The changes move in $3 \%$ from the sample with fall height $230 \mathrm{~J}$ and $50 \mathrm{~J}$. The sample with the optimal fall height $50 \mathrm{~J}$ in comparison with $230 \mathrm{~J}$ shows the change around $3 \%$. Also in this case it is enough to use the fall height $50 \mathrm{~J}$ for the sample penetration.

\subsection{Deformation after the test}

After the drop weight test the samples were photographed for better idea about the crack growth.

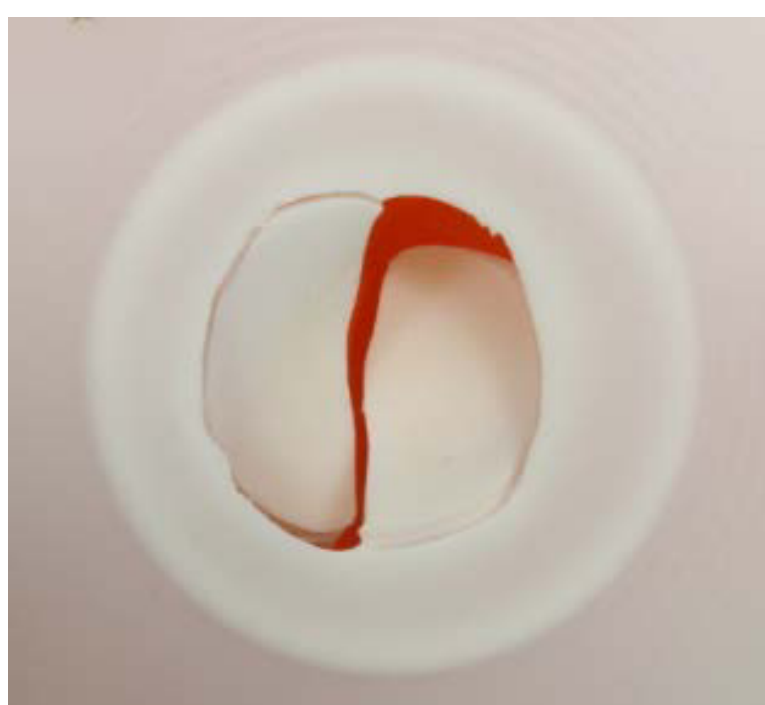

Fig. 4. HIPS deformation after drop weight test at $30 \mathrm{~J}$.

In Figure 4 the growth of the main crack continuing around the edge is displayed.

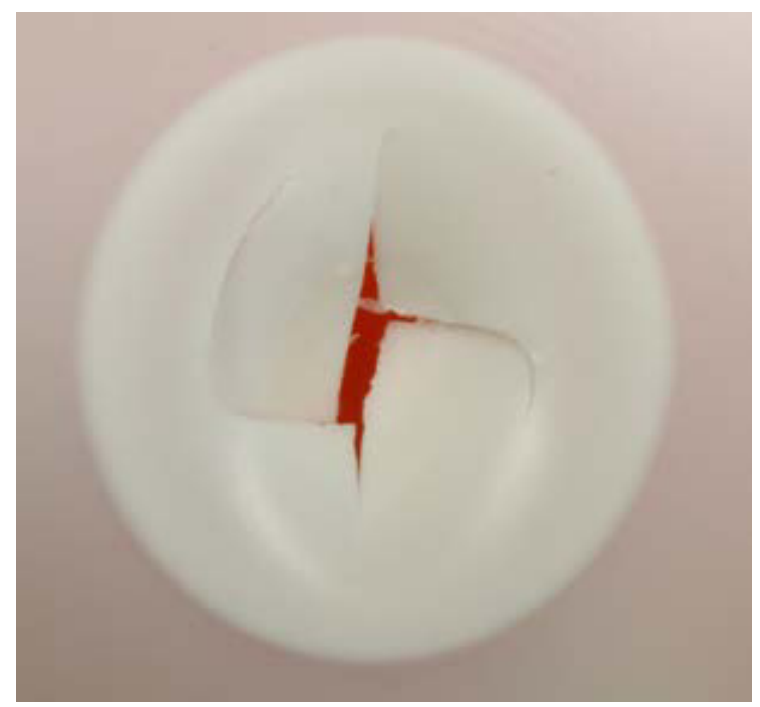

Fig. 5. HIPS deformation after drop weight test at $50 \mathrm{~J}$.

In Figure 5 the growth of the main crack and perpendicular crack with continuing around the edge is shown.

In Figure 6 and 7 the growth of the main crack and perpendicular crack with brake around the edge on one side is shown.

In Figure 8 and 9 there is clearly visible that these fall heights cause complete hole in the sample which copies the penetrator shape. 


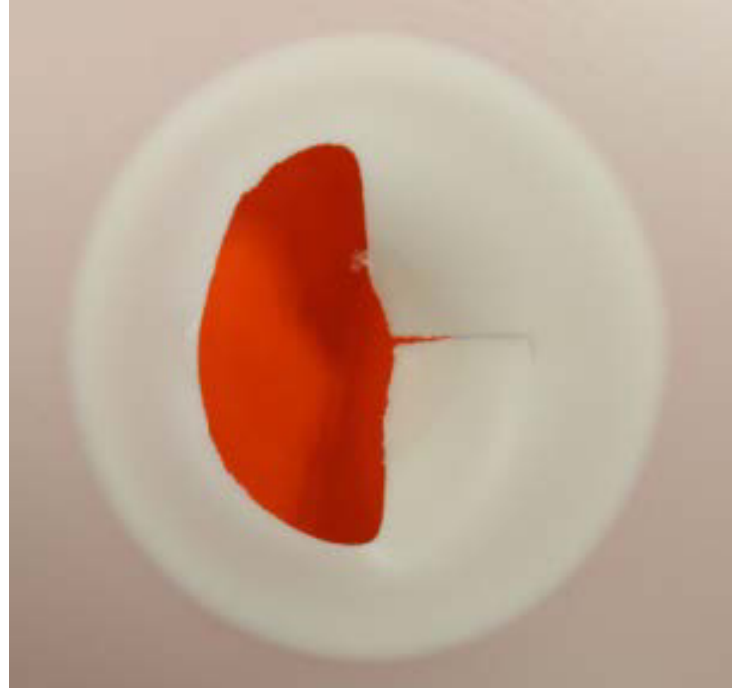

Fig. 6. HIPS deformation after drop weight test at $100 \mathrm{~J}$.

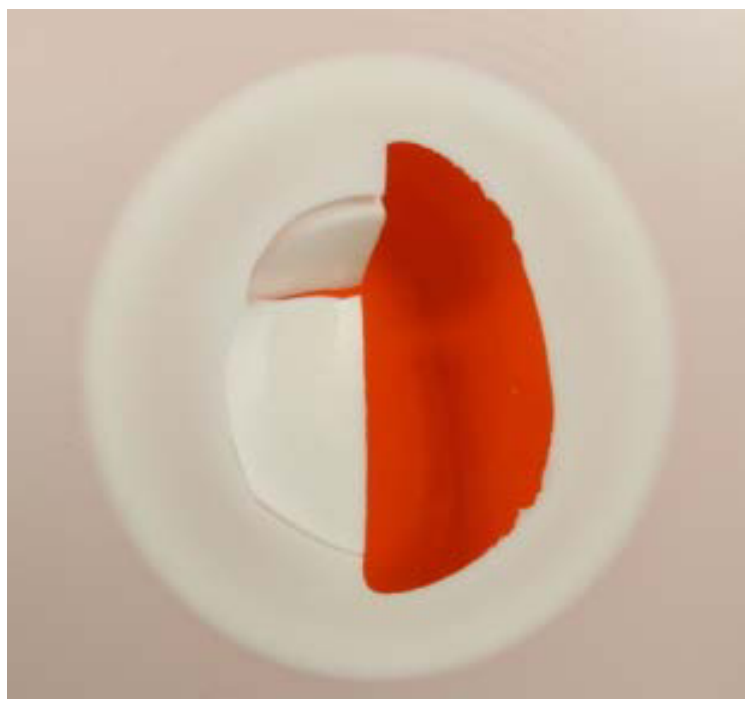

Fig. 7. HIPS deformation after drop weight test at $150 \mathrm{~J}$.

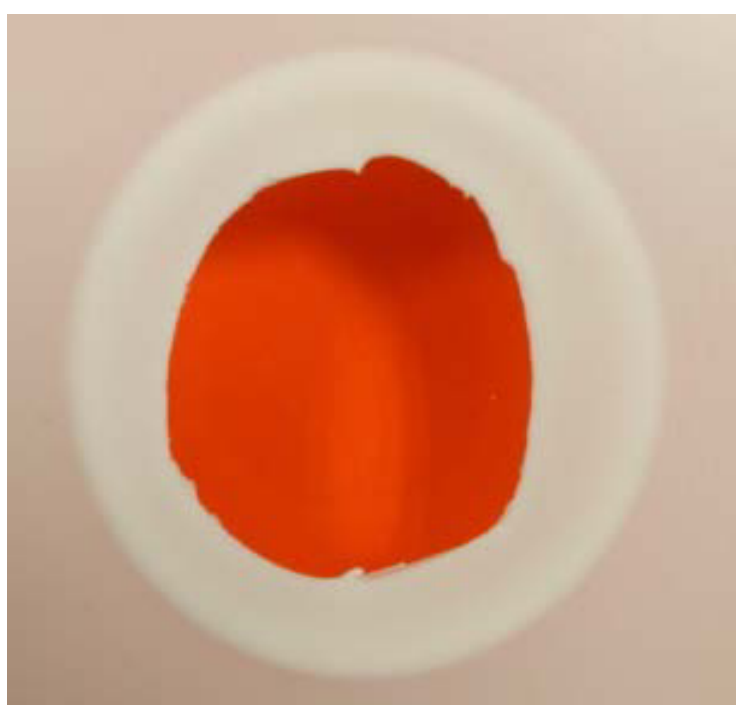

Fig. 8. HIPS deformation after drop weight test at $200 \mathrm{~J}$.

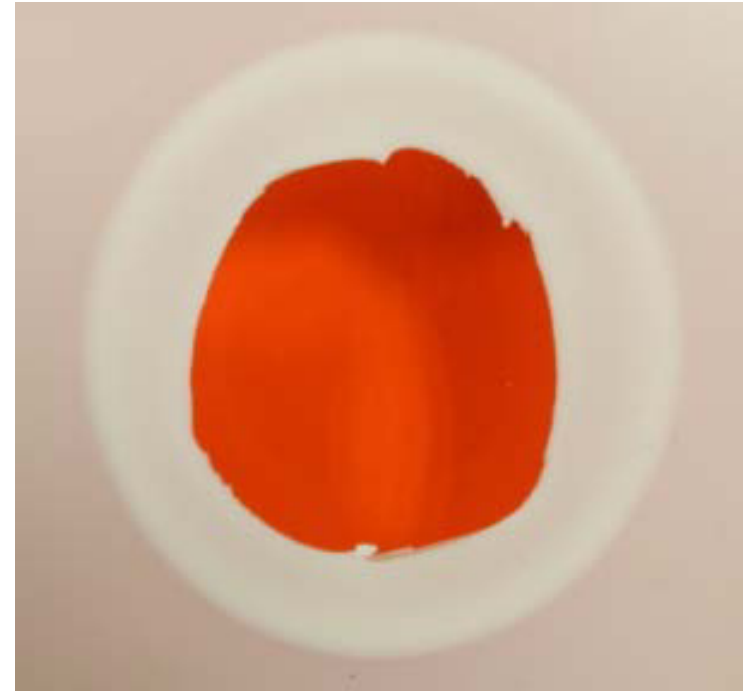

Fig. 9. HIPS deformation after drop weight test at $230 \mathrm{~J}$.

\section{Summary}

In this study the injection moulded HIPS samples were subjected the test of falling penetrator at different fall heights. The range of fall heights was from 30 to $230 \mathrm{~J}$. All these fall height cause the sample penetration. The value $50 \mathrm{~J}$ looks like the optimal because of the smallest variation range. The values from 100 to $230 \mathrm{~J}$ are not needed to use because of increasing power consumption of the test device. The conclusion of this study is that the fall height $50 \mathrm{~J}$ is the optimal for the penetration of HIPS.

\section{Acknowledgment}

This paper is supported by the internal grant of TBU in Zlin No. IGA/FT/2017/010 funded from the resources of specific university research and by the Ministry of Education, Youth and Sports of the Czech Republic within the National Sustainability Programme project No. LO1303 (MSMT-7778/2014) and also by the European Regional Development Fund under the project CEBIATech No. CZ.1.05/2.1.00/03.0089.

\section{References}

1. T.V. Khanh, Theor. Appl. Fract. Mec. 29 (1998), $75-83$

2. T. Sahin, T. Sinmazcelik, A. Arici. J. Mater. Sci. 39 (2004), 2543-2546

3. T. Yilmaz, T. Sahin, T. Sinmazcelik, J. Mater. Sci 44 (2009), DOI 10.1007/s10853-009-3640-3, 4308-4314

4. J.H. Choi, K.H. Ahn, S.Y. Kim, Polymer 41 (2000), 5229-5235

5. V. Serpooshan, S. Zokaei, R. Bagheri, J. Appl. Polym. Sci. 104 (2007), 1110-1117

6. P. Antich, A. Vázquez, I. Mondragon, C. Bernal, Composites: Part A 37 (2006), 139-150 